\title{
Conhecimento, ética e política: premissas da Pós-graduação
}

\section{Knowledge, ethics and politics: premise for Graduate Programs}

\author{
Alzira Ma Baptista Lewgoy ${ }^{a}$ \\ (1) https://orcid.org/0000-0002-7312-3111 \\ Rosa Maria Castilhos Fernandes ${ }^{a}$ \\ (D) https://orcid.org/0000-0001-5499-714X \\ Tatiana Reidel ${ }^{a}$ \\ (D) https://orcid.org/0000-0002-8590-3836
}

\begin{abstract}
Resumo: 0 artigo considera dois importantes desafios como forma de demonstrar o compromisso do Programa de Mestrado em Política e Serviço Social com, a saber: a construção de conhecimentos, em defesa da classe trabalhadora como um desafio permanente; e a implicação ética e política para produção de conhecimento como premissa para a formação no PPG.
\end{abstract}

Palavras-chave: Serviço Social. Política Social. Pós-graduação. Conhecimento. Ética.

\begin{abstract}
This article two challenges as means of illustrating the Politics and Social Work Graduate Program's commitment: knowledge building, as a permanent challenge to defend the working class; and ethical and political implications to building knowledge as an education premise on the Graduate Program.
\end{abstract}

Keywords: Social Work. Social Policy. Graduate program. Knowledge. Ethics. 


\section{Introdução}

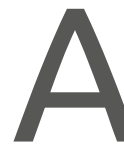

universidade como instituição inserida na sociedade capitalista é carregada de contradições e, no caso de países periféricos como o Brasil, dependente das economias capitalistas, acaba subordinado pelo processo de acumulação de capital no plano mundial que impõe, assim, adaptações de suas estruturas produtivas internas às exigências dos países dominantes (Filgueiras, 2019). Essa lógica condiciona também a conformação da educação superior, assim como a valorização ou não das universidades na construção de conhecimentos científicos e tecnológicos para o desenvolvimento humano, social, econômico, político, cultural e ambiental de uma sociedade. Trata-se de economias subordinadas e, por isto, possuem um grau de autonomia pequeno e tem como característica a transferência contínua de renda e riqueza para os países centrais (imperialistas) do sistema capitalista mundial.

A educação ao longo da história se institucionaliza para "gerar e transmitir um conjunto de valores que legitimam os interesses dominantes, como se não pudesse haver nenhuma alternativa à gestão da sociedade" (Mészáros, 2008, p. 35). Por isto a complexa e contraditória tarefa de resistir às matrizes ideológicas da educação formal de reprodução da acumulação do capital e das desigualdades sociais provocadas pela restrição de acesso às universidades que vigorou por décadas no Brasil. Entretanto, no contraponto e de acordo com as realidades sociais, políticas e culturais, processos democráticos são defendidos e se instauram entre os movimentos alavancados por diferentes sujeitos comprometidos com a construção de outra sociabilidade que reconheça o papel da educação e suas estruturas na produção da ciência e tecnologia a serviço da humanidade.

As reflexões que aqui trazemos evidenciam o risco de alguns princípios como as questões éticas e políticas que dão sentido à universalidade das universidades e, em especial, das instituições públicas de ensino superior naquilo que diz respeito à sua criação, à sua memória, à sua cultura e às produções de conhecimentos. Em que pesem as diferenças 
dos contextos territoriais em que as universidades se desenvolvem, assim como com relação ao perfil da população que acessa esses espaços formativos, não há como negar que a universalidade ${ }^{1}$ das instituições públicas universitárias no Brasil encontra-se ameaçada. De acordo com Schwartzman (1989, p. 36) "é esta universalidade, por sua vez, que explica e justifica o interesse intelectual e a profundidade da chamada questão universitária".

As agendas das políticas sociais em curso no Brasil, tensionadas pela lógica do capital, pela austeridade que respalda o desmonte do Estado democrático de direito, são evidenciadas na condução do planejamento e contrarreformas que vêm sendo implementadas pelo Ministério da Educação, colocando a questão universitária pública no "olho do furacão", sob todas as formas de ataques. Em 2019, os contingenciamentos nas verbas discricionárias no campo da política de educação atingiram todos os níveis e etapas educacionais, acabando por inviabilizar um conjunto de programas como aqueles ligados à educação superior, ${ }^{2}$ como as bolsas de pesquisas de iniciação científica, docência e de pós-graduação, os cortes de editais, que fomentam pesquisas na área de ciências humanas e das ciências sociais aplicadas, colocando em risco a continuidade de um conjunto de estudos e pesquisas. A disputa pelo orçamento público é um ponto de pauta fundamental a ser destacado quando nos referimos à efetivação de direitos sociais, como o acesso e a permanência na educação superior pública, seja na graduação ou nos PPGs.

Outras iniciativas do governo brasileiro, como o programa Future-se, voltado para as universidades e institutos federais com a explícita proposta de transferência da gestão das atividades-fim das Ifes para organizações sociais e a reforma administrativa que vem sendo desenhada no

1 A palavra "universidade" com origem no latim universitas é comumente relacionada com "universalidade, conjunto, totalidade". O termo "unus"também é utilizado em palavras como "universal" e "universo", todas referindo-se ao conceito de unidade.

2 Sobre orçamento, sugerimos ver texto disponível em: https://g1.globo.com/educacao/noticia/2019/09/13/orcamento-do-governo-federal-preve-cortes-para-educacao-basica-em-2020. ghtml. Acesso em: 9 jan. 2020. 
campo do serviço público federal, ensaiam movimentos que dão margem a passos largos na privatização das universidades. É preocupante, ainda, os questionamentos feitos pelo pensamento conservador, da ordem moral, dos ditados pelo capital, com apelos midiáticos que negam os fatos, os estudos científicos, os dados quantitativos e qualitativos que demonstram a situação brasileira em diferentes aspectos, sejam ambientais, econômicos, sociais, entre outros, que devem ser considerados para a formulação de agendas de políticas sociais, colocando o Estado numa posição de planejamento a serviço das necessidades sociais da sua população.

Por outro lado, as manifestações convocadas para o dia 15 de maio de 2019 levaram às ruas, em diferentes cidades do Brasil, a população universitária, sindicatos, segmentos dos movimentos sociais, entre outros, que se manifestaram contra as privatizações das instituições e empresas públicas, contra os cortes em pesquisas, na educação em geral, contra as agressões direcionadas pelas falas governamentais, criminalizando um conjunto de servidores públicos, entre outras violações de direitos da classe trabalhadora. Tais manifestações da questão social colocam na ordem do dia a necessária resistência que deve ser feita permanentemente pelos sujeitos da educação superior no país.

É importante reconhecer que o processo de expansão e democratização da educação superior brasileira na última década dos anos 2000 de fato ocorreu, como os avanços provocados pela inserção de estudantes de baixa renda, negros e negras, indígenas, enfim trabalhadores e trabalhadoras que vão exigir a construção de uma universidade plural, intercultural e que caracteriza a diversidade brasileira. No que diz respeito aos avanços dos PPGs, a área do Serviço Social representa 0,8\% dos programas existentes no Sistema Nacional de Pós-Graduação. A maior expansão ocorreu a partir do ano 2000, sendo que em 2018 foram identificados 36 PPGs da área em funcionamento no país e em 2015 foi aprovado o mestrado em Serviço Social e Política Social na UFRGS.

Assim, no contexto de corrosão dos direitos conquistados pela classe trabalhadora, do agravamento da desigualdade social e pobreza da 
população, da austeridade vigente, dos ataques em nome da "ideologia" é que vem se dando a consolidação do PPG Política Social e Serviço Social da UFRGS e nele profissionais do Serviço Social e de outras áreas do conhecimento vêm ingressando desde 2016. No ano de 2019, o PPG instituiu as ações afirmativas com cota étnico-racial e encontra-se atento às particularidades da região que são materializadas por meio dos objetos de estudos e das pesquisas construídas no processo de formação do programa.

Este artigo considera dois importantes desafios como forma de demonstrar o compromisso do programa com o desenvolvimento social e regional na sociedade, a saber: a construção de conhecimentos em defesa da classe trabalhadora como um desafio permanente; e a implicação ética e política para a produção de conhecimento como premissas para a formação no PPG.

\section{Construção de conhecimentos em defesa da classe trabalhadora: desafio permanente}

O campo científico, apesar de sua normatividade, é permeado por conflitos e contradições e também campo de disputa de poder, porque trata de uma matéria poderosa: o conhecimento (Minayo, 2001). Para Abramides (2019), em tempos em que é evidenciado o conhecimento aplicado, instrumental e imediato, forjado por uma universidade subordinada aos interesses privados e parte de oligopólios mercantis do ensino, é imprescindível que a produção do conhecimento tenha vinculação a um conhecimento crítico no âmbito das ciências humanas e sociais, contribuindo para a plena emancipação política e humana, por meio da socialização de informações, de forma efetiva e comprometida com as reais necessidades humanas presentes na sociedade em cada tempo histórico.

O Serviço Social, ao assumir uma direção sociopolítica e de produção de conhecimento de viés crítico, sintoniza-se frente aos desafios colocados na realidade social, reconhecendo a importância da pesquisa 
no balizamento do trabalho profissional, no avanço de sua produção intelectual e seu papel "na formação de uma cultura ideopolítica e teórica no campo da esquerda marxista” (Mota, 2013, p.19). Reconhecer isso implica pensar sobre a finalidade das pesquisas no atendimento das demandas sociais da população, que não surgem de maneira isolada, eventual, mas a partir de uma raiz comum, de um projeto coletivo de conhecimento dado por uma perspectiva mais ampla, tornando-se impossível atuar isoladamente no percurso da pesquisa. São nas relações entre os grupos, linhas e temáticas de pesquisas que são afloradas as perplexidades que levam às indagações sobre o contexto sócio-histórico possibilitando-nos sintonia e, principalmente, apontando motivos para 0 ato de pesquisar.

É nessa tessitura que o PPG em Política Social e Serviço Social da UFRGS inicia suas atividades em 2016, sendo o primeiro na área em instituição pública no estado. Sua trajetória encontra-se atrelada à criação do curso de graduação em Serviço Social (julho de 2009), uma demanda histórica atendida para oferta de ensino público e gratuito, acrescido da possibilidade de expansão do Programa de Apoio ao Plano de Reestruturação e Expansão das Universidades Federais - Reuni. Com esse contexto foram criadas condições de contribuir com a construção de investigações que resultam de um projeto pedagógico que tem como eixos articuladores o estudo da Política Social e o Serviço Social como área do conhecimento, considerando as múltiplas expressões da questão social no contexto das relações entre Estado, classes sociais e sociedade na implementação das políticas sociais no Brasil, enquanto mecanismo de proteção social, considerando a corrosão dos direitos da classe trabalhadora em curso.

A produção científica e técnica de docentes e discentes apresentam concentração em duas linhas de pesquisas: Estado, sociedade, políticas sociais; e a linha fundamentos do Serviço Social, trabalho e formação, voltadas ao âmbito do Serviço Social nas dimensões formativas, de produção de conhecimentos, incidência e intervenção profissional nas políticas sociais. Trata-se de um compromisso com a afirmação do horizonte 
social, ético e político do projeto profissional por meio da formação de profissionais qualificados acadêmica, científica e profissionalmente.

O programa oportuniza o estudo sobre as concepções e desafios da relação entre Política Social e Serviço Social, considerando o redimensionamento dos espaços sócio-ocupacionais e os impactos das transformações do trabalho. Volta-se também para a análise e investigação de caráter teórico-prático sobre temas relacionados aos fundamentos e formação em Serviço Social, ao trabalho profissional no âmbito das políticas sociais (saúde, assistência social, previdência, educação, sociojurídico, entre outras), à gestão das políticas sociais, às expressões da questão social, entre outras temáticas correlatas, envolvendo situações de diferentes sujeitos, como crianças, adolescentes, juventudes, idosos, migrantes, trabalhadores, indígenas. Enfim, parte de parâmetros histórico-críticos, intersetoriais e interdisciplinares, considerando os processos de análise das experiências engendradas por diferentes sujeitos sociais, na perspectiva de emancipação política e humana.

A produção do conhecimento a serviço da classe trabalhadora é um ato ético e político, razão pela qual a importância das condições que são o solo em que se formam o sujeito, os domínios de saber e as relações com a verdade.

\section{A implicação ética e política no PPG}

A ciência tem influência em nossa vida e é fundamental para a sociedade, mas ela só tem sentido se tem responsabilidade e incorpora valores que se filiam a uma perspectiva crítica e emancipatória que defende intransigentemente os direitos humanos, o que possibilita a potência ética e política de um PPG. É partindo dessa premissa que reconhecemos a necessidade de ampliar a compreensão da dimensão ética no campo da pesquisa científica e produção de conhecimento, problematizando sobre a amplitude de sua concepção para além da concepção de regras ou normas, envolvendo a intencionalidade e a finalidade social da investigação, 
considerando o compromisso com a pluralidade, a diversidade e a responsabilidade com os seres humanos envolvidos (Reidel, 2019).

A ética aqui parte da compreensão de que a mesma é a ciência que estuda, discute e reflete sobre a moral e, para isso, busca a filosofia e também se constitui como possibilidade dela. Permite o aprofundamento no campo de análise, indagação crítica sobre seu objeto: a moral. A ética definida nessa perspectiva diferencia-se de uma ética abstrata, discursiva, cuja implicação concreta não se manifesta nas relações sociais cotidianas (Barroco, 2000).

A dimensão ética e política que se busca efetivar no Programa de Pós-Graduação de Política Social e Serviço Social da UFRGS — PPGPSSS não se restringe a uma disciplina e/ou se limita aos aspectos normativos e deontológicos, pois ela precisa se consolidar por meio de uma formação crítica que permitirá aos pós-graduandos contribuírem com o avanço da ciência, tecnologia e da cultura, considerando a educação para além do capital, como refere Mészáros (2008).

A ética, assim como a ontologia e a epistemologia, precisa andar de mãos dadas no processo investigativo e de produção de conhecimentos. A partir da dimensão ética far-se-ão questionamentos cruciais sobre a finalidade da pesquisa e/ou produção, indagando quanto à ampliação da qualidade do conhecimento e da vida das pessoas nela envolvidas (Rios, 2006). Afinal, são indagações que permitem questionamentos do pesquisador sobre a investigação, perpassando também o trabalho dos docentes e mestrandos pesquisadores, dos grupos e núcleos de pesquisa. A indagação "se vale, sim, da explicação que a ciência oferece para os fenômenos, mas procura ir adiante, problematizando os valores envolvidos nas descobertas, criações, investigações e intervenções da ciência na realidade" (Rios, 2006, p. 83). O PPGPSSS vem criando e consolidando grupos e núcleos de pesquisas na direção de afirmação da pluralidade, considerando a perspectiva da totalidade, das lutas sociais, das classes e das contradições das políticas sociais e do próprio trabalho profissional apreendida pela “razão dialética”, como citado por Barroco (2011). 
São tempos cujos debates sobre a atualidade do legado de Marx fomentam a fúria frenética das posições antimarxistas e anticomunistas, associadas à crença de uma suposta doutrinação político-ideológica impregnada nos espaços educacionais e culturais (Simionatto, 2019). Nesse contexto, torna-se ainda mais desafiadora a filiação ética e política dos pesquisadores. Contudo, são nos limites desse processo que a produção de conhecimento precisa fazer sentido por meio de estudos e pesquisas que contribuam na busca pela consolidação de uma nova ordem societária, enfrentando o desafio de interferir nos rumos da história em favor da vida e da emancipação humana. O discurso sobre a ética é ainda abstrato, pois distintos sujeitos se referem a ética sem explicitar o seu significado, a sua direção, o projeto que defendem (Barroco, 2011).

É necessário não apenas produzir conhecimentos, mas avançar nas análises sobre o impacto social dos mesmos, na democratização dos resultados envolvendo os sujeitos participantes e instituições, na contribuição das pesquisas com a formulação das agendas das políticas sociais, com a construção de estratégias junto à classe trabalhadora, entre outros fatores e iniciativas pedagógicas de disseminação de conhecimentos. $\mathrm{O}$ debate e a apreensão da ética é uma estratégia política-pedagógica no processo de formação no PPGSS, para que os novos pesquisadores se alinhem à perspectiva histórico-crítica e de totalidade, de superação da alienação e das relações mercantilizadas que se desenham nos cenários de formação acadêmica.

Por fim, os egressos do PPGPSSS têm incidido no aprimoramento da gestão pública e no desenvolvimento regional. Observamos como parte do planejamento estratégico do programa, por meio do processo de monitoramento da situação de 24 egressos(as) do PPG (até março de 2019), que dos 22 respondentes, 81,7\% são assistentes sociais e 18,3\% de outras áreas; $72,7 \%$ são alunos(as) trabalhadores(as), com jornada de trabalho de quarenta horas semanais, com liberação para o mestrado, mas com restituição da carga horária; 79,9\% são servidores públicos e se encontram atuando no âmbito das políticas sociais; 9,6\% em empresas privadas e $10,5 \%$ se inseriram em programas de doutoramento. 


\section{Considerações finais}

As reflexões aqui socializadas são parte de um processo em construção, de fundamentos que respaldam a caminhada do PPG, que vem se aperfeiçoando por meio de um conjunto de iniciativas instituídas que têm como pressupostos: um projeto ético-político comprometido com a defesa intransigente dos direitos humanos e, portanto, da classe trabalhadora; uma orientação político-pedagógica para o PPG construída coletivamente pela Abpess; a indissociabilidade do ensino, pesquisa e extensão, considerando o necessário diálogo com a graduação em Serviço Social; a interlocução com os territórios regionais e os espaços em que os mestrandos se inserem profissionalmente ou de militância nos processos de resistências. Enfim, pressupostos que vêm acolhendo a diversidade dos perfis dos discentes que ingressam no programa e corroboram com a universalidade para o acesso na educação superior pública.

Também temos o entendimento de que a produção científica dos PPG - neste caso o PPGPSSS da UFRGS - , a partir das premissas expostas, possibilita sair do lugar-comum, avançar cientificamente e se constituir como forma de desvendar, evidenciar, declarar e resistir às violações que assolam a sociedade brasileira. É uma maneira de romper, de dar visibilidade ao real para além do aparente, ampliando perspectivas e ultrapassando a conformidade ante os preconceitos, a moralidade liberal da ordem, do controle, da dominação, contribuindo e/ou interferindo para possibilidades emancipatórias e novos caminhos possíveis que se firmam na direção ética e política.

Seguimos avançando nas produções, deixando nelas a memória e os registros deste tempo presente de um país que vive o desmonte de um conjunto de políticas públicas que afetam diretamente as condições de vida da população. Continuaremos investindo em estudos e pesquisas que escrevam e retratem essa dimensão sócio-histórica, que revelem resultados trazidos pelos sujeitos participantes e que façam sentido para as pessoas, os processos de gestão e controle social-democrático das políticas sociais públicas, as lutas e movimentos sociais, as populações 
discriminadas, enfim tudo aquilo que for trazido como objeto de estudo que esteja em sintonia com o projeto societário que defendemos, porque, como diz Elza Soares, "nós não vamos sucumbir".

\section{Referências}

ABRAMIDES, Ma Beatriz C. O projeto ético-político do Serviço Social brasileiro: ruptura com o conservadorismo. São Paulo: Cortez, 2019.

BARROCO, Ma Lucia S. Barbárie e neoconservadorismo: os desafios do projeto ético-político. Serviço Social \& Sociedade, São Paulo, n. 106, p. 205-218, abr./jun. 2011.

BARROCO, Ma Lucia S. Ética e sociedade. Brasília: CFESS, 2000.

FILGUEIRAS, Luiz. O "future-se" no capitalismo dependente brasileiro. Le Monde Diplomatique Brasil, n. 145, 27 ago. 2019. Disponível em: https://diplomatique.org.br/ofuture-se-no-capitalismo-dependente-brasileiro/. Acesso em: 10 jan. 2020.

MÉSZÁROS, István. A educação para além do capital. Tradução Isa Tavares. 2. ed. São Paulo: Boitempo, 2008.

MINAYO, Ma Cecília de S. (Org.) et al. Pesquisa social: teoria, método e criatividade. 19. ed. Rio de Janeiro: Vozes, 2001.

MOTA, Ana Elizabete. Serviço Social brasileiro: profissão e área de conhecimento. Revista Katálysis, Florianópoils, v. 16, 2013.

REIDEL, Tatiana. Ética na pesquisa: implicações para além da formalidade. In: MENDES, Jussara M. R.; WÜNSCH, Dolores S.; GIONGO, Carmem R. (Orgs.). A investigação no campo da saúde do trabalhador: construção do conhecimento e estratégias metodológicas. Campinas: Papel Social, 2019. p. 207-224.

RIOS, Terezinha A. A ética na pesquisa e a epistemologia do pesquisador. Psicologia em Revista, Belo Horizonte, v. 12, n. 19, jun. 2006. Disponível em: http://pepsic.bvsalud.org/ scielo.php?script=sci_arttext\&pid=S1677-11682006000100008. Acesso em:14 jan. 2020.

SCHWARTZMAN, Simon. Universalidade e crise das universidades. Estudos Avançados, São Paulo, jan./abr. 1989. Disponível em: http://www.scielo.br/scielo.php?script=sci_ar ttext\&pid=S0103-40141989000100004. Acesso em: 14 jan. 2020.

SIMIONATTO, Ivete. Serviço Social, reação conservadora e o ataque ao marxismo. In: SILVA, Ma Liduína de O. O Congresso da Virada e o Serviço Social hoje: reação conservadora, novas tensões e resistências. São Paulo: Cortez, 2019. p. 117-135. 


\section{Sobre as autoras}

Alzira Ma BAptista LeWgoy - Pós-doutora em Serviço Social. Universidade Federal do Rio Grande do Sul; professora do Departamento de Serviço Social e do Programa de Pós-Graduação de Política Social e Serviço Social.

E-mail: alzira.lewgoy@ufrgs.br

Rosa Maria Castilhos Fernandes - professora do Departamento de Serviço Social e coordenadora do Programa de Pós-Graduação de Política Social e Serviço Social

E-mail: rmariacf@uol.com.br

Tatiana Reidel - Doutora em Serviço Social, professora do Departamento de Serviço Social e do Programa de Pós-Graduação de Política Social e Serviço Social E-mail: tatyreidel@gmail.com 